\title{
Partidos políticos importam na definição de carreiras políticas no Brasil?
}

\author{
Vitor Eduardo Veras de Sandes-Freitas' \\ Diarlison Lucas Silva da Costa ${ }^{2}$
}

\section{Resumo}

Este artigo tem como objetivo verificar se os partidos políticos são importantes na definição da escolha de carreira política dos deputados federais brasileiros. Para tanto, este trabalho parte das contribuições sobre carreira política que têm demonstrado que o principal padrão de carreira apresentado pelos deputados federais é o estático, ou seja, a busca por reeleição (PEREIRA; RENNÓ, 2013). A explicação apontada é a de que essa escolha é a mais segura eleitoralmente, independentemente dos partidos aos quais eles são filiados. Entretanto, outros autores têm chamado a atenção para a necessidade de se verificar a importância de fatores que diferenciem os deputados para uma análise mais desagregada das carreiras políticas como a participação na coalizão de governo ou nos grupos de oposição (BORGES; SANCHES FILHO, 2016), assim como as diferenças apresentadas dentro dos distritos (COSTA, 20I8; CORRÊA, 20I6). Além disso, a variável partidária pode ser um fator importante para a definição das carreiras, devido às diferenças ideológicas dos partidos (MARENCO; SERNA, 2007) e aos interesses estratégicos dos partidos nas disputas para Prefeito nas grandes cidades (GRAÇA; SOUZA, 20I4). Assim, este artigo visa a testar se a variável partidária importa para a escolha de carreira de deputados federais, assim com as demais variáveis retratadas pela literatura. Os resultados encontrados mostram que os deputados de partidos de esquerda e da coalizão de governo têm maior probabilidade de concorrer à reeleição e a prefeituras do que os de direita e de centro.

Palavras-chave: Carreiras políticas. Partidos políticos. Deputados federais.

\footnotetext{
I Professor Adjunto de Ciência Política - Universidade Federal do Piauí (UFPI). Coordenador do Grupo de Pesquisa sobre Partidos Políticos (GEPPOL-UFPI).E-mail: vitorsandes@ufpi.edu.br

2 Atualmente, cursa doutorado em Ciência Política pela Universidade Estadual de Campinas (UNICAMP). Mestre em Ciência Política pela Universidade Federal do Piauí (UFPI). E-mail: diarlison.lucas2@gmail.com
}

\section{$(\mathrm{cc}) \mathrm{Br}$}

Direito autoral e licença de uso: Este artigo está licenciado sob uma Licença Creative Commons. Com essa licença você pode compartilhar, adaptar, para qualquer fim, desde que atribua a autoria da obra, forneça um link para a licença, e indicar se foram feitas alterações. 


\section{Introdução}

O debate sobre a construção de carreiras políticas no Brasil tem enfatizado, em grande medida, a relação entre as regras eleitorais e as escolhas dos políticos. No que se refere aos deputados federais, o argumento principal é o de que o legislativo brasileiro não apresenta um nível significativo de institucionalização e consequentemente de profissionalização da carreira legislativa; por este motivo, não há interesse dos deputados em nutrir o desejo pela permanência neste cargo (SAMUELS, 2003, 2011). Os estudos que desenvolvem este argumento levam em consideração a ambição individual dos deputados e náo focam sua atençáo na relação que eles mantêm com seus partidos nem em como a sua afiliação partidária pode afetar sobre suas decisóes de carreira.

Um problema de pesquisa comum que permeia grande parte dos estudos sobre carreiras políticas se refere à explicação da direção que os políticos escolhem seguir ao concluírem seus mandatos, se pretendem avançar a cargos mais atrativos, buscar estender o atual mandato ou disputar cargos mais baixos. Grande parte das explicaçóes para esses tipos de decisóes toma como ponto de partida a ambição individual dos políticos observada como fenômeno determinado, primordialmente, pelo seu desejo de sobreviver politicamente (PEREIRA; RENNÓ, 2013; LEONI; PEREIRA; RENNÓ, 2015).

A ideia comum que transita nesses trabalhos é a de que, uma vez eleito, um político trabalhará com o intuito de buscar meios para a manutenção de sua carreira política, seja tentando permanecer em seu atual cargo, seja buscando outros cargos que permitam sua sobrevivência política ou ascensão na carreira. A segunda ideia é que, se for oferecido um cargo mais atrativo a um político sem que haja custos envolvidos na disputa, este certamente o aceitará (ROHDE, 1979; KIEWIET; ZENG, 1993). Ou seja, as atividades exercidas pelos políticos são função de sua ambição política, por exemplo, um deputado com a intenção de concorrer ao Senado tenderia a ampliar a atuação legislativa, tentaria angariar mais recursos para suas bases, e investiria na imagem pessoal frente ao seu eleitorado. De outro lado, um deputado mais vulnerável, por exemplo, um que estivesse envolvido em um escândalo de corrupção, que não enxergasse a possibilidade 
de concorrer a cargos mais competitivos, tenderia a buscar a sobrevivência, ou permanecendo no mesmo cargo ou se candidatando a um cargo menos atrativo, como o de deputado estadual. Entretanto, não é possível afirmar que a vontade individual per se é o único motivo para as decisóes dos políticos ao decidirem concorrer novamente (COSTA, 2018).

A teoria da ambição política apresenta um modelo formal importante para pesquisas sobre carreira política ao tipificar as escolhas de cargos por "ambiçóes", e pela teorização do cálculo de utilidade realizado pelos políticos (SCHLESINGER, 1966; BLACK, 1972; ROHDE, 1979; ABRAMSON; ALDRICH; ROHDE, 1987). Entretanto, mapear as ambiçôes individuais e os fatores que as condicionam é uma tarefa que acarreta muitas dificuldades; e, para contornar esse problema, grande parte dos pesquisadores tenta encontrar fatores que tenham relação com as escolhas feitas sobre os cargos que os políticos buscam ao final de seus mandatos (COSTA, 2018). Captar as ambiçôes é um empreendimento muito difícil por se tratar de um aspecto subjetivo e não mensurável.

Para encontrar explicaçóes sobre as escolhas de carreiras, os estudos enfatizam o comportamento dos políticos em duas arenas principais: na arena eleitoral e na arena de atuação no Estado, seja no Executivo ou no Legislativo. No que se refere aos deputados, federais ou estaduais, é comum a ideia de que a atuação legislativa, seja na proposição de leis, relatoria de projetos, ou trade for pork, está relacionada com os prospectos de carreira de cada político (SAMUELS, 2000; 2003; PEREIRA; RENNÓ, 2013; LEONI; PEREIRA; RENNÓ, 2015). Outra forma comum de se analisar as escolhas de carreira dos deputados é observar sua atuação eleitoral dentro do distrito, seja pela busca de ampliação de sua base eleitoral, ou através de credit claiming por políticas defendidas ou pelos porks (na forma de emendas orçamentárias) direcionados a uma circunscrição territorial.

Os estudos sobre esse tema no Brasil seguem a perspectiva da construção de campanhas personalizadas. Carey e Shugart (1995) observaram que as regras do sistema eleitoral brasileiro influenciam nos tipos de campanha que os deputados realizam; ou seja, nas eleiçôes proporcionais, as campanhas são focadas na imagem dos candidatos e náo na dos seus partidos. Esse fato seria explicado pela possibilidade de atuação de muitos partidos 
em distritos de grandes proporçóes, com alta magnitude, e sob um sistema de lista aberta, fatores que, quando combinados, engendrariam um alto nível de competitividade dentro e fora da lista do partido ou da coligação. Dessa forma, as campanhas eleitorais dependeriam quase inteiramente da figura do candidato e do seu potencial de agregar votos.

De maneira diversa ao que acontece em sistemas de lista fechada, em que os candidatos são selecionados para a formação da lista e todos os votos são recebidos pelo partido, no sistema de lista aberta os candidatos não figuram em uma lista fixa, eles são selecionados e disputam as cadeiras com todos os demais candidatos no distrito, e contra os seus colegas de chapa. Esse fato leva ao aumento da competição, pois o candidato precisa se sobressair a todos os outros (CAREY; SHUGART, 1995). Contudo, essa perspectiva observa os efeitos do sistema eleitoral como formatador do comportamento eleitoral e considera constantes as características dos partidos. Por esse caminho, a explicação do comportamento dos candidatos desvia o ângulo de observação de fatores que não as regras do sistema eleitoral como as características das unidades subnacionais e dos partidos políticos (SAMUELS, 1997).

Dessa forma, em um cenário político regido pelo sistema de lista aberta que favorece a campanha centrada no candidato, seria de se esperar que os cálculos feitos por ele levassem em consideração sua performance e o seu histórico eleitoral. Ou seja, a escolha de carreira seria uma função da ponderação de fatores, por exemplo: a votação já obtida, o seu potencial em arrecadar financiamento para a campanha, já ter ocupado um alto cargo anteriormente, ser incumbente, o tipo de votação obtida, se esta é concentrada ou dispersa, entre outros (PEREIRA; RENNÓ, 2013; COSTA, 2018).

Seguindo essa perspectiva, muitos estudos sobre carreiras políticas desenvolvidos no Brasil observaram o potencial eleitoral dos candidatos como os fatores determinantes de suas escolhas de carreira (PEREIRA; RENNÓ, 2013). Apesar de essas abordagens sobre as performances individuais terem apresentado importantes resultados para o entendimento dos comportamentos dos políticos e de suas carreiras, ainda restam questóes sobre como essas variáveis são influenciadas por fatores externos aos indivíduos 
como as características contextuais e institucionais distintivas de seus distritos, e pela sua afiliação a partidos de tamanhos e ideologias diferentes (BOTERO; RENNÓ, 2007).

Apesar das variáveis referentes aos candidatos, como sua capacidade de agregação de votos, serem primordiais para a sua escolha de carreira, elas não explicam por inteiro as trajetórias por eles seguidas. É necessário observar como os interesses dos partidos políticos convergem com os interesses de carreira dos candidatos. Os diferentes partidos apresentam interesses e características específicas que possibilitam aos atores individuais oportunidades diferentes. Dependendo do acesso a recursos que uma agremiação partidária dispóe, de sua posição em relação ao governo e sua definição ideológica, a formação da lista pode variar para atender a interesses coletivos diversificados. Os políticos apresentam seus anseios sobre a disputa eleitoral, mas são os líderes partidários os responsáveis pela designação da lista, que será definida de acordo com o contexto da competição e de acordo com o potencial eleitoral de cada candidato.

Nesse sentido, o objetivo do artigo é verificar se os partidos políticos são importantes na definição da escolha de carreira política dos deputados federais brasileiros, no período de 2006 a 2014. Para tanto, o artigo foi estruturado em três seçóes, além desta introdução e da conclusão. Na primeira seção, é apresentada a literatura sobre carreira política no Brasil, com foco nos deputados federais, trazendo contribuiçóes sobre como os partidos políticos podem afetar a construção de diferentes padróes de carreira entre os parlamentares brasileiros. $\mathrm{Na}$ segunda, apresentam-se as escolhas metodológicas para a realização dos testes propostos para este artigo. Por fim, a última seção apresenta os resultados dos testes estatísticos e a discussão desses resultados.

\section{Carreiras políticas e estrutura de oportunidades}

Uma das formas de controle partidário sobre as candidaturas está na avaliação do potencial dos candidatos para a formação das listas. $\mathrm{O}$ sistema eleitoral permite que os partidos apresentem até uma vez e meia a quantidade de cadeiras disponíveis no distrito; em caso de coligação, podem apresentar até o dobro de candidatos, mas esse número varia de acordo 
com a quantidade de cadeiras que o distrito disponha. Segundo Braga e Amaral (2013), apesar de os partidos terem a possibilidade de apresentar o total de candidatos permitidos, são poucos os que o fazem, pois preferem lançar candidaturas estratégicas capazes de concentrarem votos e se alçarem ao topo da lista, como o caso dos "puxadores de votos", o que garante um relativo controle dos líderes partidários sobre a seleção para o alcance de objetivos específicos.

Além do lançamento estratégico de candidatos, os partidos também se valem de distribuição diversificada socialmente de candidaturas no interior da lista como forma de reduzir a competição intralista e atingir diversos tipos de composiçôes sociais do eleitorado (BRAGA; AMARAL, 2013). A literatura já demonstra que os partidos têm controle sobre a formação geral da lista de candidatos, mas não se sabe ao certo em que medida os políticos já eleitos são selecionados para disputar os cargos disponíveis no período eleitoral. Dessa forma, surge o seguinte problema: é possível afirmar que os partidos tenham algum controle relativo sobre as decisóes de carreira dos deputados federais incumbentes? Qual o papel dos incumbentes na formação da lista partidária?

Samuels (2003) observou que a influência da estrutura partidária sobre os incumbentes é mínima e que o contexto institucional presente no Brasil é marcado pelo alto nível de personalização das campanhas nas eleiçóes proporcionais. Portanto, a busca do voto pessoal seria um dos fatores mais pungentes que caracterizariam o momento da escolha dos deputados que apresentariam constante ambição progressiva, e atuariam no Congresso na medida de suas ambiçóes.

Um dos resultados aos quais chegou Samuels (2003), é que o cargo legislativo é pouco profissionalizado no Brasil, e a explicação para esse fato está na conformação institucional dada pela Constituição de 1988 que garante ao presidente grande poder de agenda e aos líderes partidários, no Congresso, grande poder de controle sobre suas bancadas. A pouca possibilidade de autonomia na atuação legislativa, principalmente no sistema de comissóes, diminuiria o desejo pela construção de carreiras legislativas longevas, e, por conseguinte, a um diminuto intuito em fortalecer a Instituição. As eleiçóes em grandes distritos com magnitudes variáveis tam- 
bém são um fator que dificultaria a consolidação de carreiras legislativas na Câmara por dificultar, em grande medida, a reeleição. Portanto, os políticos, ao analisarem um contexto muito arriscado e competitivo para um cargo com baixo nível de profissionalização, tenderiam a alimentar o desejo por cargos executivos no nível subnacional, pois esses cargos proveem maiores recursos que podem ser utilizados em disputas futuras, para si e para seus partidos.

Embora a explicação de Samuels (2000) para o alto nível de renovação dos quadros da Câmara dos Deputados ter como um dos principais elementos a propensão de os políticos buscarem cargos mais atrativos, um fenômeno ainda chama a atenção: em média $74 \%$ dos deputados federais concorrem à reeleição; destes, cerca de dois terços apenas conseguem se reeleger. Embora o percentual de reeleição não seja tão alto, a quantidade dos que se reapresentam ainda é alta. Segundo Pereira e Rennó (2013), apesar de o cargo de deputado federal não ter alto nível de profissionalização, a explicação para o alto percentual de tentativa de reeleição seria porque essa é a alternativa mais segura para os deputados. Ao avaliarem sua situação e projetarem potencial de alcance de cargos mais altos, a maioria dos deputados tenderia a se reapresentar para o mesmo posto como forma de sobreviver politicamente.

Leoni, Pereira e Rennó (2015) afirmam que os partidos têm pouca influência sobre as decisóes de carreiras individuais, porque o processo de formação da lista se dá dentro dos partidos estaduais descentralizados e não em uma estrutura partidária nacional centralizada. Cada candidato teria, assim, de buscar alianças estaduais ou municipais para garantir sua eleição e centralizar em si o alvo dos votos. Isso não só dificultaria o controle partidário nacional sobre as candidaturas dos incumbentes como também faria com que estes priorizassem o atendimento de clientelas como forma de nutrir sua carreira posterior.

Embora a literatura considere que os partidos escolhem os deputados possuidores de maior potencial eleitoral para as disputas mais concorridas (BRAGA, AMARAL 2013), ainda restam questôes sobre os padróes de competição entre os deputados, e sobre como partidos diferentes podem moldar padróes de carreira divergentes em seus afiliados. Por este motivo, 
o objetivo deste trabalho é verificar se é possível constatar variações nas escolhas de carreiras dos deputados federais brasileiros no que se refere à sua alocação em partidos com diferentes posiçóes ideológicas e com diferentes tamanhos e formas de organização.

Nesse trabalho advogamos que, para se entender com relativa profundidade as escolhas dos deputados, é necessário um maior entendimento sobre os fatores externos que influenciam nessas decisóes. A estrutura de carreiras, o sistema partidário e as características dos distritos necessitam ser analisadas para a concretização desse objetivo. Por conseguinte, enfatizamos, neste estudo, como os partidos influenciam nas decisôes de carreiras dos deputados federais brasileiros.

Em primeiro lugar, a estrutura de oportunidades institucionais no Brasil proporciona uma grande possibilidade de cargos e direçóes de carreira para os políticos (BORCHERT, 2009, 2011). No período das eleiçóes gerais, os deputados federais podem optar por diversos cargos; mas, a escolha depende de sua inclinação pessoal, dos seus atributos políticos, e a sua capacidade de congregar votos é um dos principais fatores que explicam escolha de sua posição na lista do partido.

Essa estrutura complexa de oportunidades engendra também uma grande dificuldade em mapear os padróes de carreira no Brasil por permitir muitos movimentos em diversas direçóes. Essa idiossincrasia do sistema eleitoral brasileiro levou Borchert (2011) a denominar a estrutura de carreiras no país de "integrada". Essa tipologia se refere à estrutura desenvolvida pelos diversos movimentos de carreira dos políticos que não é conformada em padrôes imediatamente identificáveis, nem com uma direção unilinear.

Segundo Borchert (2009, 2011), as estruturas de carreiras em países com sistema federativo são caracterizadas pela sua possibilidade de movimentação entre os níveis nacional e subnacional, e podem apresentar um padrão de ascensão do local ao nacional ou por movimentos variados entre essas esferas. No Brasil, essa estrutura é caracterizada pela escolha de direçôes opostas. Não há uma ascendência estrita do nível local para o nacional como há em outros países. Esse fato é explicado pela alta atratividade dos cargos executivos e pela baixa profissionalização dos cargos legislativos (deputado Federal e Estadual - o cargo de senador é caracterizado como 
cargo mais alto e mais atrativo), que tem como consequência alto percentual de tentativa de retorno dos deputados federais às bases estaduais para manutenção da vida política. Assim sendo, o tipo integrado é caracterizado pela falta de fronteiras bem delimitadas entre os níveis de governo, com uma hierarquia de cargos é praticamente inexistente e, por permitir muitas direçôes de carreira, admite grandes chances de um político permanecer no jogo político.

O cargo de deputado federal, como um cargo no nível nacional, ainda apresenta grande atratividade pelo nível de visibilidade que pode oferecer quando comparado a outros cargos como o deputado estadual e vereador. Entretanto, como observou Samuels (2003), esse cargo ainda tem o potencial de ser um trampolim para outros, principalmente para prefeituras. É um cargo importante tanto para o político quanto para o partido, pois possibilita o acesso a muitos recursos, como acesso a repasses do governo federal, e a execução de emendas orçamentárias (a execução de emendas não é realizada pelos parlamentares que a conseguem, mas pelo chefe do executivo para onde elas são destinadas).

Essa característica da Câmara como uma "casa de passagem" pode ser constatada pelo baixo percentual de mandatos consecutivos que os deputados detêm. A média de mandatos exercidos pelos deputados federais na nossa amostra $^{3}$ é de 2,45 , ou seja, a maioria dos deputados não tenta construir carreiras duradouras no Legislativo. Uma explicação para isso é que muitos desses deputados buscam candidatar-se a outros cargos, e outros ocupam o mandato apenas como forma de se manterem no jogo político e retornarem a disputar os cargos antes ocupados, como é o caso de prefeitos que concluem o limite de dois mandatos, tentam a disputa para a Câmara e, dois anos depois, tornam a disputar a prefeitura antes ocupada.

No que se refere ao sistema partidário, o diagnóstico comum é que os partidos brasileiros se constituem de organizaçóes com estruturas nacionais fracas; por esse motivo, o processo de formação das listas acontece no nível subnacional. Dessa forma, as lideranças partidárias estaduais deteriam

3 Nossa amostra é composta por 1463 deputados federais titulares dos partidos PT, PSB, PMDB, PSDB, DEM e PP, entre 2002 e 2014. 
maior poder sobre as candidaturas. Esse fato levaria à emergência de bancadas heterogêneas na Câmara dos Deputados (MAINWARING, 1991). Contudo, apesar de o processo de seleção acontecer no nível estadual, os partidos ainda teriam problemas em controlar as candidaturas dado o perfil de campanha engendrado pelo sistema eleitoral (SAMUELS, 2008).

A disposição dos partidos entre situação ou oposição de governo também é um fator que ajuda a explicar diferentes padróes de carreiras no Brasil. De acordo com Borges e Sanches Filho (2016), os deputados federais de partidos que estão na coalizão de governo em nível nacional e estadual apresentam maior probabilidade de concorrer à reeleição, pois detêm maior possibilidade de obter recursos políticos e, assim, maior segurança quanto a concorrer novamente. Por outro lado, os deputados de oposição têm maior probabilidade de concorrer a cargos no executivo, pois não encaram os mesmos riscos que os de situação e não têm níveis altos de disputa interna nos partidos. Fato que pode ser explicado pelo perfil anterior dos candidatos e dos partidos.

Partidos com orientaçôes ideológicas e tamanhos diferentes necessitam conseguir cargos, mas o seu acesso a recursos é variado. Partidos menores náo têm o mesmo potencial em lançar candidaturas a disputas majoritárias em grande quantidade e por esse motivo é comum se esperar que integrem coalizóes com outros partidos a fim de maximizar seu resultado eleitoral (BORGES; SANCHES FILHO, 2016). Esse e outros fatores podem levar os integrantes desses partidos a apresentarem padróes diversificados de carreira tendo em vista a sua probabilidade de êxito e a determinaçáo dos líderes partidários.

Supomos que, uma vez que partidos pequenos consigam postos legislativos, a sua intenção será maximizar esse ganho e manter seus deputados na disputa à reeleição, e que partidos maiores com acesso a recursos mais robustos tenderáo a apresentar candidatos a cargos mais altos, e, ainda, que a orientação ideológica e a disposição dos partidos em relação aos governos também influenciariam as candidaturas a depender do partido que ocupe o cargo no Executivo.

Um dos primeiros pontos a ser destacado é o curto carreirismo legislativo no Brasil. Apesar de termos uma complexa e grande estrutura de 
oportunidades, o objetivo de construir carreiras longevas no Legislativo não é o objetivo primeiro dos políticos no país. A explicação para este fato já é apontada pela literatura que relaciona a menor possibilidade de acesso a recursos que os cargos legislativos dispóem em comparação com os cargos executivos (SAMUELS, 2000, 2003). Devido à possibilidade que os deputados têm de concorrer a cargos executivos em meio ao mandato (o cargo de prefeito) sem a necessidade de renunciar ao seu cargo, essa escolha torna-se muito atrativa e de baixo risco aos que tentam (KLASNJA; TITIUNIK, 2017; COSTA, 2018). Esse é um passo muito comum tomado por deputados. De fato, $16 \%$ dos deputados presentes em nossa amostra decidiram concorrer a prefeituras durante seus mandatos.

A Câmara dos Deputados gera poucos incentivos para que os deputados federais possuam ambição estática, pela forma centralizada como o Legislativo é organizado no Brasil, ou seja, centrado nos líderes partidários (FIGUEIREDO; LIMONGI, 2004). O desenho institucional do Legislativo gera poucos incentivos para que os deputados federais construam carreiras fortes junto às comissóes, em razão da centralização dos trabalhos legislativos nos líderes. Assim, uma parte pequena dos deputados federais possui relevância política dentro dos partidos para poder pleitear cargos de maior ambição: Prefeituras, Senado, Governos estaduais e Presidência da República. Deputados federais que possuem "ambição progressiva", portanto, necessitariam ter as condiçôes para progredir individualmente e, uma delas, seria ter projeção junto ao partido, o que poderia atrair recursos do partido e financiadores para alavancar suas candidaturas a cargos mais altos.

O argumento de Samuels (2000) sobre este ponto é que a alta competitividade geraria incentivos para que deputados federais menos relevantes tentem a reeleição, ou seja, mantendo a ambição estática. No entanto, conforme Leoni, Pereira e Rennó (2015, p. 64), não é possível afirmar que a ambição estática seja desejada apenas por deputados federais menos relevantes. Nas palavras dos autores: "[...] a maioria absoluta dos políticos que detêm uma posição poderosa na Câmara prefere permanecer nessa casa”. Assim, não se pode atribuir somente aos indivíduos a motivação de se optar por uma ambiçáo estática ou progressiva. Os partidos políticos podem ter potencial de atuação no sentido de incentivar a ambição progressiva 
(considerando a relevância dos cargos em disputa, como Prefeituras e Governos estaduais) ou a ambição estática (reforçando as bancadas do partido no Legislativo). Se as escolhas de carreira dos deputados federais podem afetar o espaço político ocupado pelos partidos, é possível que elas não sejam escolhas puramente individuais, mas também partidárias.

Sobre isso, Graça e Souza (2014) argumentam que os partidos possuem menor controle sobre as escolhas dos deputados federais que disputam cargos proporcionais. No entanto, isso não se aplicaria às cidades maiores, já que

[...] a decisão sobre a candidatura de um prefeito numa cidade média ou grande é uma escolha importante para o partido, que é tomada algumas vezes, inclusive, pelo diretório nacional. Para o partido, lançar um nome para a prefeitura é uma decisão que depende, entre outras coisas, de negociá-lo com outros partidos quando se participa de uma coligação eleitoral, por exemplo. Por isso, podem existir custos para o partido que permite a um deputado ou outro candidato qualquer se lançar numa disputa em determinada circunstância. Pouco se sabe sobre a estratégia adotada para realizar a escolha dos nomes que disputam as eleições municipais. Parece razoável imaginar que as lideranças escolham os nomes com mais chances de sucesso. (GRAÇA; SOUZA, 2014, p. 343).

Talvez isso não se restrinja somente às grandes cidades, pois cidades médias, por exemplo, podem ter capacidade de arrecadação maiores do que de muitas cidades grandes, tornando-as estratégicas para os partidos. Em suma, um deputado federal pode buscar ser eleito prefeito nos municípios também por incentivo dos partidos, não somente por razóes puramente individuais. O custo, em teoria, seria baixo para os políticos, pois não perdem seus mandatos ao concorrerem às eleiçóes municipais, visto que elas ocorrem no meio do mandato. $\mathrm{O}$ risco maior pode estar envolvido em deixar de concorrer à reeleição para tentar um cargo maior: Governo do Estado, Senado e Presidência. Nesses casos, é possível que os partidos tenham menor gerência sobre as decisóes dos deputados federais, pois envolvem custos muito altos aos políticos, porque a quantidade de vagas em disputa, no caso de ambição progressiva, é muito menor do que de cadeiras para a Câmara dos Deputados. Ainda assim, é relevante testar as diferenças entre os partidos no padrão de escolhas de carreiras de deputados federais (se pela ambição estática ou progressiva), principalmente nas eleiçóes para Prefeito. 
Graça e Souza (2014) observam que a opção em concorrer à prefeitura durante o mandato tem efeitos eleitorais positivos no pleito subsequente para aqueles que não logram êxito na campanha. Esse fato pode ser um indicativo de que os candidatos e os partidos usem esse processo como forma de proporcionar a busca por resultados melhores em outro momento, como nas eleiçóes seguintes, pois abriria um leque maior de oportunidades que podem ser pleiteadas por esses indivíduos, como a reeleição ou cargos maiores.

Além do foco na conquista de grandes cargos e na manutenção de outros estratégicos, os partidos políticos também podem interferir, em alguns casos, no sentido de pressionar que um filiado se lance a cargos menores ou mesmo que se aposente, considerando situaçóes em que a escolha pela ambição estática seja danosa ao partido pelo fato de esse candidato ter uma alta chance de derrota eleitoral.

O que podemos afirmar até o momento é que, apesar de ser muito difícil apreender as ambiçóes individuais e seus determinantes, assim como as formas de influência da estrutura partidária sobre os incumbentes em um sistema multipartidário, os interesses individuais e coletivos são intercambiáveis; logo, é necessária uma abordagem que consiga entender, conjuntamente, as motivaçóes individuais e partidárias do processo de construção de carreiras políticas no Brasil.

Para que um partido tenha sucesso em formar uma bancada numerosa e alçar a cargos executivos, ele precisa lançar seus candidatos com maior potencial competitivo em eleiçóes que têm sido muito disputadas. Sáo muitos os partidos e os candidatos que disputam as eleiçôes em seus respectivos distritos eleitorais, no caso brasileiro, nos estados. Esse fato torna o nível de competitividade política um dos principais fatores para que os partidos busquem diferentes formas de formação das listas (COSTA, 2018).

A pressão partidária para que um candidato concorra a um determinado cargo é de difícil mensuração e demandaria um trabalho qualitativo em profundidade. Entretanto, observamos que os partidos possuem interesses específicos com as candidaturas. Sabemos que os partidos de esquerda no Brasil, antes de 2002, lançavam muitos de seus deputados federais bem conhecidos a cargos executivos como forma de ampliar sua capacidade de 
votação nos municípios. O caso que mais chama atenção é o do Partido dos Trabalhadores (PT) que, em 1998, lançou 36\% de seus deputados incumbentes a cargos mais altos e apenas $56 \%$ à reeleiçáo para a Câmara. A partir de 2006, o PT passou a adotar outra estratégia; então, o percentual de seus incumbentes que concorreram à reeleição naquele ano foi de $88 \%$ passando a $74 \%$ em 2010 e a $76 \%$ em 2014.

Sobre essas diferenças entre os partidos, Marenco e Serna (2007), analisando os casos do Brasil, Chile e Uruguai, verificaram que os padróes de carreira dos políticos não são homogêneos, tendo diferenciaçóes entre os partidos, conforme suas vinculações ideológicas. Os autores partem do pressuposto que "[...] o eixo ideológico esquerda/direita é uma dimensão relevante na organizaçáo do sistema e dos partidos políticos dos três sistemas multipartidários" (MARENCO; SERNA, 2007, p. 64); por isso, analisar as escolhas de carreira somente a partir das variáveis individuais, a partir de um cálculo de custo-benefício centrado somente em interesses puramente individuais não tem ressonância na realidade política, em que os partidos possuem diferentes padróes de recrutamento político, conforme seu posicionamento ideológico.

Olhando somente para o caso brasileiro, foco deste artigo, as agremiaçóes analisadas pelos autores foram: o Partido Progressista Brasileiro (PPB) - atual Partido Progressista (PP), o Partido da Frente Liberal (PFL) - atual Democratas (DEM), à direta; o Partido do Movimento Democrático Brasileiro (PMDB) e o Partido da Social Democracia Brasileira (PSDB), ao centro; e o Partido dos Trabalhadores (PT), à esquerda. Estes têm sido os principais partidos brasileiros desde a redemocratização, que têm conduzindo governos, participando de coalizóes e, consequentemente, ocupando importantes postos ministeriais, controlando as maiores bancadas do Congresso, elegendo governadores e prefeitos nas grandes cidades brasileiras.

Marenco e Serna (2007, p. 108) encontraram que os deputados dos partidos conservadores (e, neste caso, eles incluíram o PMDB, além do PFL e do PPB) têm carreiras "[...] apoiadas em estruturas mais flexíveis, partidos do tipo catch-all [...] e com trajetórias partidárias iniciadas tardiamente e menos contínuas"; já os políticos de partidos à esquerda (neste 
caso, o PT) possuem carreiras baseadas “[...] em longas trajetórias e na fidelidade partidária, apoiada em estruturadas do tipo profissional eleitoral”. ${ }^{4}$

As carreiras políticas em partidos de direita seriam projetadas pelo próprio prestígio e recursos individuais que os políticos possuem. Com isso, "[...] detendo recursos próprios - como prestígio, renda e relações estabelecidas pela ocupação profissional, os candidatos não dependem do aval partidário, podendo ignorá-lo com menor risco para o ingresso ou a continuidade em sua carreira" (MARENCO; SERNA, 2007, p. 109). Por outro lado, em partidos de esquerda, o controle partidário das carreiras políticas é muito sólido, o que indicaria que estariam propensos a seguir as orientaçôes das lideranças partidárias e, consequentemente, as estratégias da organização.

Em consonância com esses achados e fazendo um balanço da produção sobre recrutamento e carreiras políticas, Marenco (2013, p. 44) afirma que os partidos de esquerda são caracterizados como organizaçáo com "[...] maior diversificação social na composição social dos seus eleitos, bem como vínculos partidários mais duráveis e prévios ao início da carreira política”. Já os partidos de direita, ou partidos tradicionais, “[...] recrutam seus candidatos com capital eleitoral pessoal e carreiras construídas prévia e externamente a vínculos partidários estáveis" (MARENCO, 2013, p. 44). Assim, definitivamente, a variável "partido político" parece importar para compreendermos as escolhas de carreira dos políticos.

Ainda sobre os partidos políticos brasileiros, é importante considerar que entre 1994 e 2014 preponderou um padrão de disputas presidenciais na política brasileira que influenciou a dinâmica político-partidária do país: a polarização entre PT e PSDB. Devido ao alinhamento das eleições nacionais, presidentes, governadores, senadores, deputados federais e estaduais passaram a ser escolhidos no mesmo pleito, o que foi um grande incentivo institucional para o alinhamento entre as candidaturas presidenciais e estaduais. As disputas nos estados, principalmente dos governadores,

4 É importante fazer uma ressalva à citação dos autores. Não é possível afirmar que os partidos de direita seriam menos programáticos do que os partidos de esquerda. É possível que os partidos de esquerda flexibilizem seus discursos para abarcar um eleitoral mais moderado, o que também poderia os aproximar de um modelo catch-all. Os partidos de direita podem ser programáticos, mesmo que os vínculos dos políticos com os partidos sejam frágeis. 
tenderam a ser impactadas por essa dinâmica bipolarizada entre PT e PSDB (BRAGA, 2006; MELO, 2007; CORTEZ, 2009; LIMONGI; CORTEZ, 2010; MENEGUELLO, 2010; MELO; CÂMARA, 2012; SANDES-FREITAS, 2015).

Em torno do PT e do PSDB, foi possível identificar a formação de dois blocos claros: de um lado, o PT, o Partido Socialista Brasileiro (PSB), o Partido Democrático Trabalhista (PDT) e o Partido Comunista do Brasil (PCdoB), e, do outro, o PSDB, o DEM e o Partido Popular Socialista (PPS), conforme Melo e Câmara (2012). Os autores ainda destacam a existência de um bloco formado por PMDB, PP, PTB e PR, composto por partidos que estariam dispostos a participar de governos por razóes estratégicas e não ideológicas. Sandes-Freitas (2015) destaca que dos dois blocos polarizados, apresentado por Melo e Câmara (2012), PSB e PCdoB seriam mais fiéis ao PT e o DEM, ao PSDB.

Sobre o PMDB, é válido destacar que a organização passou de um partido com pretensóes nacionais nos anos 1980, principalmente por sua atuação na transiçáo à democracia, a um partido com forte vocação governista e regional (BIZZARRO-NETO; 2013; FERREIRA, 2002; MACIEL, 2014). Devido à sua grande heterogeneidade interna, o partido não tem conseguido viabilizar uma candidatura presidencial com chances reais de vitória. As últimas foram de Orestes Quércia em 1994, que obteve 4,4\% dos votos válidos, e Henrique Meirelles, em 2018, que teve apenas 1,2\% da preferência dos eleitores, apesar de este ter o controle da presidência da República naquele ano. Assim, é um partido que busca construir bancadas amplas para poder ser um player importante no processo de formação de governos.

Pensando a variável partidária como importante para a compreensão das escolhas de carreira dos deputados federais brasileiros, analisaremos se os partidos com "vocação presidencial", como PT e PSDB - nos termos de Melo e Câmara (2012) - buscariam cargos de maior relevância nas eleiçóes municipais, que ocorrem em anos não coincidentes às eleiçóes nacionais. Para tanto, esses partidos poderiam estar lançando mais deputados federais como candidatos às Prefeituras do que partidos como o PMDB, estes que, apesar de historicamente lançarem muitos candidatos à prefeitura, 
tendem a focar sua atenção em municípios menores (SANDES-FREITAS, 2013), o que pode não ser estratégico para deputados federais. O mesmo caso pode ser pensado para outro partido relevante nacionalmente, o PP (ex-PDS, PPR e PPB), que passou de uma organização central na transição democrática para um partido governista e com desempenho eleitoral desigual regionalmente (KERBAUY, 2009), com força destacada na região Sul do país (SANDES-FREITAS, 2013).

Nesse sentido, tomamos os argumentos apresentados pela literatura para pensar as escolhas de carreira dos deputados federais brasileiros. A questão colocada é: em que medida as variáveis partidárias explicam a escolha de carreira ao longo do mandato do deputado federal no Brasil?

\section{Metodologia, hipóteses e escolha de casos}

Em consonância com o debate teórico, e conforme os propósitos do artigo, as hipóteses são as seguintes. A hipótese 1 é: os deputados federais de partidos mais à direita e ao centro concorrem menos à prefeitura do que de partidos à esquerda, pois em partidos de direita há menor controle do partido sobre as escolhas dos políticos do que em partidos de esquerda, ou seja, estão mais suscetíveis às orientaçóes nacionais do partido. Como a estratégia de ocupar prefeituras pode ser interessante aos partidos, do ponto de vista de ampliar sua força nacional, é possível que os deputados federais de partidos de esquerda busquem mais as prefeituras do que os de direita e de centro por controlarem mais a formação das listas.

Já a hipótese 2 é: os deputados federais de partidos com vocação presidencialista (PT e PSDB) concorrem mais à prefeitura do que de partidos sem esta vocaçáo, devido à pretensão de esses partidos ampliarem sua força política no país. ${ }^{5}$

5 É importante frisar que partidos como PT e PSDB também podem ceder à cabeça de chapa em eleições municipais para poder garantir o apoio de outros partidos em outras disputas eleitorais. Isto, no entanto, não contraria a tese da literatura de que os partidos com "vocação presidencial” buscam disputar eleições municipais de maior relevância, como das capitais dos estados. Por isso, hipotetizamos que partidos com essa orientação teriam maior interesse em lançar seus deputados federais como candidatos a prefeitos do que os partidos sem vocação para disputas presidenciais. 
Assim, conforme foi discutido anteriormente, as questóes partidário-ideológicas são relevantes para se compreender carreiras políticas, considerando as diferenças entre os partidos de esquerda e direita e, também, suas vocações presidencialistas. Para tanto, selecionamos, para esta análise, partidos que são compreendidos pela literatura como os mais relevantes no sistema partidário brasileiro ao longo do tempo, desde a transição à democracia, seja pelo tamanho das bancadas no Congresso ou por terem sido centrais na composição de governos até 2014, sendo eles: PT, PSDB, PMDB, PSB, DEM e PP.

Esses seis partidos selecionados possuíam, juntos, em média, mais de dois terços das cadeiras na Câmara dos Deputados no período em estudo. Durante este período, os partidos presentes na amostra conseguiram eleger uma média de 367 deputados, sendo: 391 em 2002, 370 em 2006 e 340 em 2010. Em média, isso corresponde a $71,5 \%$ do total de parlamentares eleitos nessas três legislaturas. Essa amostra é composta por $344(31,2 \%)$ deputados classificados como de esquerda (PT e PSB), 432 (39,2\%) de centro (PSDB e PMDB), e 325 (29,5\%) de direita (PP e DEM).

A Tabela 1 apresenta os percentuais de candidatura para todos os cargos eletivos disponíveis aos deputados federais. A escolha pela reeleição é a mais frequente em todos os partidos e apenas o PSDB apresentou um percentual abaixo da média dos outros partidos. Por outro lado, o PT apresentou um crescimento importante no período para este mesmo cargo. Uma das explicaçóes para este crescente número é a estratégia partidária para manter apoio legislativo de sua bancada, por ser o partido que detinha o poder executivo nacional neste período. Antes da vitória do PT em 2002, o partido apresentava grandes percentuais de candidaturas a prefeituras e lançava uma média de $63 \%$ de incumbentes à reeleição, cerca de $20 \%$ a menos que os partidos de direita. ${ }^{6}$

6 Informação extraída do nosso banco de dados referente às escolhas de carreira dos deputados federais do PT em 1998 e 2002. 
Tabela I - Percentual de cargos disputados pelos deputados federais por partidos entre 2006 e $2014^{*}$

\begin{tabular}{lccccccc}
\hline Cargo & DEM & PMDB & PP & PSB & PSDB & PT & Total \\
\hline $\begin{array}{l}\text { Deputado } \\
\text { Federal }\end{array}$ & 70,9 & 78,1 & 78,9 & 76,2 & 68,4 & 79,2 & 75,4 \\
Retirou & 10,4 & 7,0 & 8,2 & 3,6 & 10,0 & 8,1 & 8,2 \\
Senador & 6,3 & 3,3 & 3,8 & 5,9 & 3,7 & 5,0 & 4,5 \\
Prefeito & 3,1 & 2,9 & 0,8 & 9,5 & 6,8 & 3,5 & 4,0 \\
$\begin{array}{l}\text { Deputado } \\
\text { Estadual }\end{array}$ & 2,1 & 3,3 & 1,5 & 1,2 & 3,2 & 1,1 & 2,2 \\
Vice-Governador & 3,1 & 2,1 & 3,0 & 1,2 & 3,7 & 0,4 & 2,2 \\
Governador & 1,0 & 2,5 & 3,0 & 1,2 & 2,6 & 1,9 & 2,1 \\
Suplente & 2,1 & 0,4 & 0,8 & 1,2 & 1,6 & 0,8 & 1,1 \\
Senador & 0,5 & 0,4 & 0,0 & 0,0 & 0,0 & 0,0 & 0,2 \\
Vice-Presidente & 0,5 & 0,0 & 0,0 & 0,0 & 0,0 & 0,0 & 0,1 \\
Vice-Prefeito & $\mathbf{1 0 0}$ & $\mathbf{1 0 0}$ & $\mathbf{1 0 0}$ & $\mathbf{1 0 0}$ & $\mathbf{1 0 0}$ & $\mathbf{1 0 0}$ & $\mathbf{1 0 0}$ \\
\hline Total & & & & & & & \\
\hline
\end{tabular}

* Dados extraídos do Tribunal Superior Eleitoral.

Fonte: Elaborada pelos autores.

$N: 1101$.

Para pontuar as diferenças entre os partidos a serem analisados, elaboramos o Quadro 1 para poder apresentar os partidos, conforme a relação entre o tipo de vocaçáo do partido quanto à disputa presencial e ao seu posicionamento ideológico, duas variáveis importantes extraídas da literatura apresentada na seção anterior. ${ }^{7}$

7 O quadro I foi elaborado com base em reflexões de Marenco e Serna (2007), Melo e Câmara (20I2) e Sandes-Freitas (2015). Especificamente quanto ao PSB, é válido destacar que o partido foi categorizado como de "vocação regional e/ou governista". Neste caso, o partido pode ser compreendido com um partido de "vocação regional" ainda que tenha lançado candidaturas presidenciais em 2002 e 2014 . A razão disso é que, além de ser um aliado frequente de candidaturas do PT para governador (que o coloca em posição de coadjuvante em relação ao PT), o partido tem força concentrada no Nordeste, principalmente em Pernambuco, base eleitoral de Eduardo Campos, candidato a presidente em 2014 pelo partido. Após o falecimento do candidato durante a campanha, foi substituído por Marina Silva, candidata a vice na chapa. 
Quadro I - Classificação dos partidos para análise, conforme a relação entre vocação e posicionamento ideológico dos partidos

\begin{tabular}{|c|c|c|c|}
\hline \multirow{2}{*}{ Tipo de vocação } & \multicolumn{3}{|c|}{ Posicionamento ideológico } \\
\cline { 2 - 4 } & Esquerda & Centro & Direita \\
\hline $\begin{array}{c}\text { Vocação } \\
\text { presidencialista }\end{array}$ & PT & PSDB & \\
\hline $\begin{array}{c}\text { Vocação regional } \\
\text { e/ou governista }\end{array}$ & PSB & PMDB & $\begin{array}{c}\text { PFL/DEM e } \\
\text { PPB/PP }\end{array}$ \\
\hline
\end{tabular}

Fonte: Adaptado de Marenco e Serna (2007), Melo e

Câmara (20/2) e Sandes-Freitas (20/5).

Para a análise aqui proposta, selecionamos três variáveis individuais dos candidatos e três partidárias que são importantes para sua escolha de carreiras: votaçáo na eleição anterior, a despesa de campanha e a quantidade de mandatos já exercidos (a quantidade de mandatos é usada como proxy para a experiência do deputado), a posição ideológica do partido, a sua vocação presidencialista e a sua participação na coalizão de governo. A unidade de análise são as decisóes de carreira que os deputados federais eleitos fizeram ao final do mandato de 2006 a $2014^{\circ}$. Os partidos são divididos em três grupos: de esquerda, centro e direita. Esperamos que os partidos de diferentes posiçóes ideológicas apresentem incentivos de carreiras divergentes.

A variável dependente são as escolhas de carreira que os deputados fizeram ao final do mandato. Dividimos essa variável em duas para efetuar análises em duas etapas. Primeiramente, desenvolvemos uma análise dos efeitos das variáveis acima expostas sobre as escolhas dos deputados, congregadas nas categorias de ambição. Em seguida, verificamos a relação

8 Trabalhamos com os deputados federais eleitos a partir de 2002 pela disponibilidade de dados. Os dados disponíveis antes desse período apresentam ausência de algumas informações como os dados relativos ao financiamento de campanha. O segundo motivo para a escolha desse período é a possibilidade de se analisar a diferença entre deputados da coalizão de esquerda centralizada no PT. Dessa forma, analisamos as escolhas que os deputados eleitos em 2002 fizeram em 2006, e, na sequência, até as escolhas realizadas em 2014 pelos deputados eleitos em 2010. 


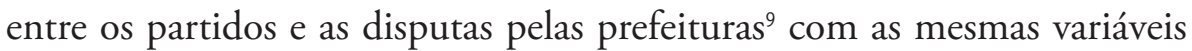
independentes. Essas escolhas foram classificadas em termos de "ambição", seguindo a definição de Schlesinger (1966). Então, classificamos quatro tipos de ambição ${ }^{10}$ : discreta, regressiva, estática e progressiva. Mantivemos as quatro categorias, de acordo com o que já vem sendo trabalhado na literatura, para permitir a comparação entre as alternativas, dado que a utilidade em se buscar um cargo está ligada à relação entre a utilidade e os custos de se buscar outro cargo. Selecionamos para este estudo apenas as escolhas por cargos eletivos como forma de verificar as estratégias dos candidatos e de seus partidos na arena eleitoral. Os deputados que assumiram postos não eletivos foram classificados na categoria ambição discreta.

Para a análise, propomos uma descrição dos dados, alguns testes de correlação para verificar se existem diferenças entre os partidos quanto às escolhas de carreira dos deputados e, por fim, uma regressão logística multinomial" e uma regressão logística binária com o modelo que incluirá as variáveis individuais acima listadas, além das variáveis relativas ao tipo de partido ao que o deputado federal é filiado.

\section{Resultados e discussão}

Para testar as hipóteses levantadas na seção anterior, construímos um banco de dados com base nas informaçóes disponibilizadas pelo TSE, referentes às candidaturas de deputados federais eleitos de 2002 até as escolhas de carreira realizadas em 2014. As variáveis escolhidas são referentes a características individuais que podem ser levadas em conta no momento da escolha dos cargos eletivos, assim como sobre as características dos partidos

9 Concorrer ao cargo de prefeito também é apresentado pela literatura como ambição progressiva. Entretanto, o objetivo de nosso estudo é verificar esta opção de maneira mais desagregada para um maior esclarecimento das estratégias partidárias.

10 Grande parte dos estudos sobre carreiras políticas no Brasil tem seguido a divisão das escolhas em quatro categorias: ambição discreta, quando o político decide não disputar a nenhum cargo; ambição regressiva, quando o candidato escolhe concorrer a um cargo mais baixo do que o ocupado; ambição estática, a decisão por buscar a reeleição; e a ambição progressiva, a escolha por cargos mais altos (SCHLESINGER, 1966; LEONI; PEREIRA; RENNÓ, 2015; SAMUELS, 2003; PEREIRA, RENNÓ, 2013, BORGES; SANCHES FILHO, 2016).

II Estudos anteriores trabalham com este modelo (PEREIRA; RENNÓ, 20I3; BORGES; SANCHES FILHO, 20I6). Apesar de este modelo não ser muito eficaz e flexibilizar o pressuposto de "Independence of Irrelevant Alternative” (IIA), ele foi escolhido para permitir maior comparação com os estudos já realizados. 
políticos na amostra. De acordo com a Tabela 2, que classifica os tipos gerais de ambição que um político pode apresentar em relação aos cargos políticos, as escolhas mais frequentes realizadas pelos deputados federais são a reeleição e a busca por cargos mais altos.

Tabela 2 - Percentual de escolhas de cargos dos deputados federais por partido entre 2006 e $2014^{*}$

\begin{tabular}{cccccccc}
\hline \multirow{2}{*}{$\begin{array}{c}\text { Tipo de } \\
\text { ambição }\end{array}$} & DEM & PMDB & PP & PSB & PSDB & PT & \multirow{2}{*}{ Total } \\
\cline { 2 - 6 } & 70,8 & 78,1 & 80,0 & 76,2 & 68,4 & 79,2 & 75,4 \\
\hline Estática & 16,7 & 11,6 & 12,0 & 19,0 & 18,4 & 11,5 & 14,2 \\
Progressiva & 10,4 & 7,0 & 7,5 & 3,6 & 10,0 & 8,1 & 8,2 \\
Discreta & 2,1 & 3,3 & 1,5 & 1,2 & 3,2 & 1,2 & 2,2 \\
Regressiva & $\mathbf{1 0 0}$ & $\mathbf{1 0 0}$ & $\mathbf{1 0 0}$ & $\mathbf{1 0 0}$ & $\mathbf{1 0 0}$ & $\mathbf{1 0 0}$ & $\mathbf{1 0 0}$ \\
\hline Total & & & &
\end{tabular}

*Dados extraídos do Tribunal Superior Eleitoral. Fonte: Elaborada pelos autores.

$N$ : 1101 .

A primeira hipótese deste trabalho refere-se à probabilidade de os deputados de partidos diferentes apresentarem comportamentos diversos em relação à disputa por prefeituras. Esta hipótese baseia-se no pressuposto de que os partidos de esquerda buscaram mais esse cargo que partidos de direita no período estudado. $\mathrm{Na}$ Tabela 3, é possível observar que os partidos de esquerda apresentaram um percentual maior para esse tipo de escolha do que as demais agremiaçóes. Durante os governos do PT, os partidos de esquerda escolhidos para a análise (PT e PSB) foram os que lançaram maior percentual de seus deputados federais à reeleição e ao cargo de prefeito. Os testes de correlação (V de Cramer e qui-quadrado) foram significativos para esta associação. ${ }^{12}$ Esse fato indica confirmação da primeira hipótese de que os partidos de centro e de direita têm menos propensão a apresentarem candidatos para as eleições municipais. No período estudado, o percentual de candidaturas para as prefeituras e à reeleiçáo aumentou

12 p-valor menor do que 0,05. 
nos partidos de esquerda, mostrou-se estável entre os de centro, e diminuiu nos partidos de direita.

Tabela 3 - Percentual de deputados federais candidatos a prefeito por ideologia partidária entre 2006 e $2014^{*}$

\begin{tabular}{lcccccc}
\hline \multirow{2}{*}{$\begin{array}{l}\text { Disputou } \\
\text { prefeitura }\end{array}$} & \multicolumn{5}{c}{ Esquerda } & \multicolumn{2}{c}{ Centro } & \multicolumn{2}{c}{ Direita } \\
\cline { 2 - 7 } & $\mathrm{N}$ & $\%$ & $\mathrm{~N}$ & $\%$ & $\mathrm{~N}$ & $\%$ \\
\hline Não & 272 & 79,1 & 367 & 85,0 & 283 & 87,1 \\
Sim & 72 & 20,9 & 65 & 15,0 & 42 & 12,9 \\
Total & 344 & 100 & 432 & 100 & 325 & 100 \\
\hline \multicolumn{5}{c}{ * Dados extraidos do Tribunal Superior Eleitoral. } \\
& \multicolumn{5}{c}{ Fonte: Elaborada pelos autores. }
\end{tabular}

A segunda hipótese deste trabalho refere-se à probabilidade de os deputados de partidos com "vocação presidencialista" buscarem mais prefeituras do que os parlamentares de outros partidos, por razóes estratégicas do PT e PSDB que focam ampliar o seu espaço político como forma de ampliar o suporte às suas candidaturas nas eleiçôes presidenciais. $\mathrm{Na} \mathrm{Ta}-$ bela 4, é possível observar que a diferença é pequena na porcentagem de deputados dos dois tipos de partidos, sendo que PT e PSDB concorreram um pouco mais a esses cargos do que os demais (17,1\% a $15,7 \%)$. No entanto, os testes de correlação (V de Cramer e qui-quadrado) não foram significativos para esta associação. ${ }^{13}$ Isso indica que não podemos confirmar a segunda hipótese de que os partidos de "vocação presidencialista", no caso PT e PSDB, têm mais propensão a apresentarem candidatos para as eleiçóes municipais do que os demais.

13 p-valor menor do que 0,05 . 
Tabela 4 - Percentual de deputados federais candidatos a prefeito por vocação presidencialista entre 2006 e $2014^{*}$

\begin{tabular}{cccc}
\hline \multirow{2}{*}{$\begin{array}{c}\text { Concorreu à } \\
\text { prefeitura }\end{array}$} & Não & Sim & Total \\
\cline { 2 - 3 } & 84,3 & 82,9 & 83,7 \\
\hline Não & 15,7 & 17,1 & 16,3 \\
\hline Sim & 100 & 100 & 100,0 \\
\hline Total &
\end{tabular}

* Dados extraídos do Tribunal Superior Eleitoral.

Fonte: Elaborada pelos autores.

Em relação à carreira legislativa, a literatura aponta que ela não é o principal foco dos deputados federais brasileiros (SAMUELS, 2003, 2008). Contudo, ao verificarmos a quantidade de mandatos exercidos pelos deputados por partido, é possível observar que, no período estudado, os deputados dos partidos de direita apresentaram média maior de mandatos, ou seja, os deputados desses partidos optaram por construir carreiras legislativas mais longevas como mostra o Gráfico 1. Analisamos isso a partir da observação da média de cargos exercidos por cada deputado e por ideologia partidária. Esse resultado não implica a inferência de que os deputados desses partidos buscam mais a reeleição, mas que essas agremiações privilegiam a manutenção de seus quadros no legislativo e promovem a permanência de seus políticos mais experientes. 
Gráfico I - Box plot da quantidade de mandatos exercidos por deputado federal por ideologia partidária com referência as eleições de 2006 a $2014^{*}$

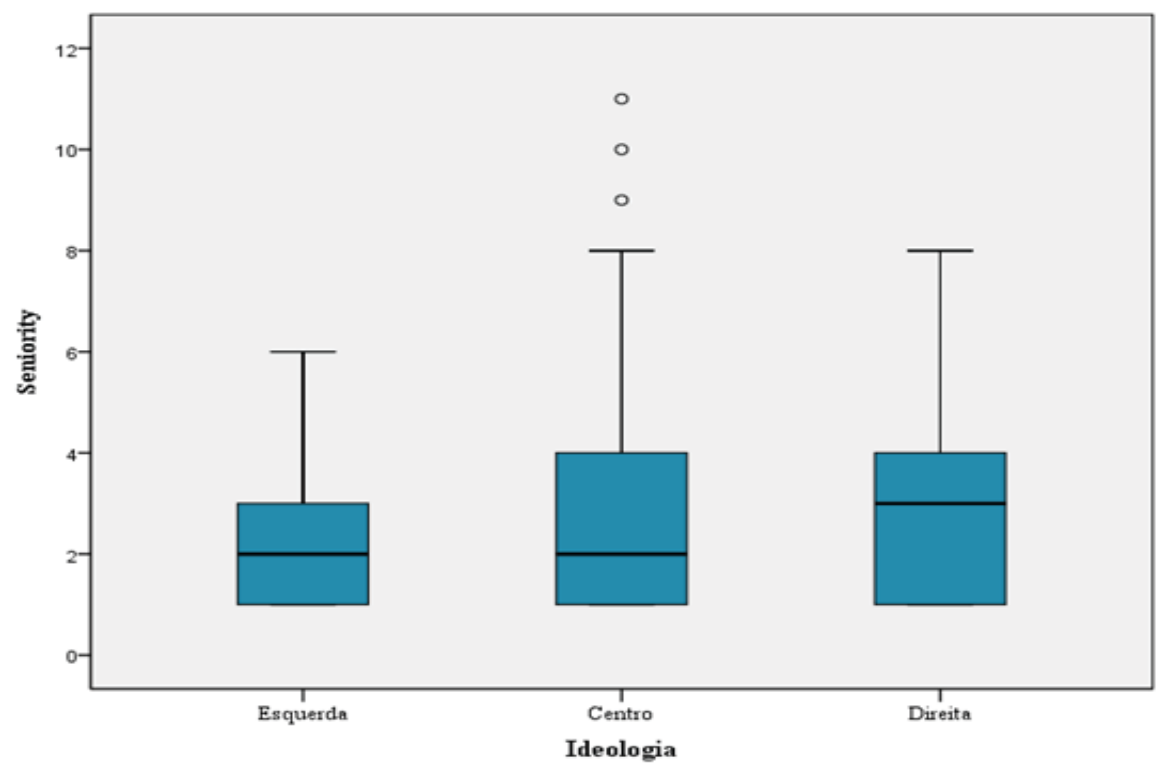

* Dados extraídos de Tribunal Superior Eleitoral.

Fonte: Elaborado pelo autor (2019).

Uma observação que pode ser aventada sobre esse fato é que os partidos de direita, por estarem na oposição durante o período em estudo, optaram por uma estratégia de "menor dano", isto é, por ter menor acesso a recursos, enquanto oposição. A estratégia menos arriscada para os candidatos e para os partidos é a manutenção de seu quadro de incumbentes, que teriam maior probabilidade de ganhar eleições menos arriscadas (comparadas a busca por cargos maiores) (BORGES; SANCHES FILHO, 2016). Dessa forma, é possível observar que fazer parte da coalizão de governo é um dos fatores mais relevantes para a decisáo de carreira definida pela avaliação dos riscos da disputa pelos candidatos e por seus partidos.

Considerando a relação entre a determinação partidária e a escolha de carreira dos deputados federais brasileiros, aplicamos testes de correlação entre a variável ambição e a ideologia do partido, sua vocação 
presidencialista e a sua participação na coalizão de governo. Tomadas essas características gerais dos partidos, não é possível observar grande influência nas decisóes de carreiras; afinal, os valores para o teste V de Cramer não resultaram significativos como mostra a Tabela 5, exceto quando analisamos a relação entre a variável coalizão de governo e ambição. O que podemos depreender do resultado da Tabela 5 é que a participação na coalizão de governo no nível federal é um fator importante para as escolhas de carreiras dos deputados federais. É certo que o controle das listas e as escolhas das candidaturas estão relacionados com a posição dos partidos, mas ainda é preciso encontrar quais fatores influenciam nesses resultados.

Tabela 5 - Correlações entre ideologia, vocação, coalizão e tipos de ambição dos deputados federais entre 2006 e 2014 (Teste V de Cramer)*

\begin{tabular}{lc}
\hline Variáveis & p-value \\
\hline Ideologia/ambição & 0,422 \\
Vocação/ambição & 0,883 \\
Coalizão/ambição & 0,015 \\
\hline
\end{tabular}

N: 1101

* Dados extraidos do Tribunal Superior Eleitoral. Fonte: Elaborada pelos autores.

A partir da observação de que os partidos detêm o controle sobre as listas apresentadas nos anos eleitorais, e que os deputados avaliam o peso político de sua agremiaçáa no momento de decidir qual cargo disputar, desenvolvemos dois modelos de regressão logística com as variáveis dependentes já apresentadas. 
Tabela 6 - Regressão logística multinomial (VD: ambição: estática vs. progressiva $)^{\star}$

\begin{tabular}{lccc} 
& Discreta & Regressiva & Progressiva \\
\hline \multirow{2}{*}{ Votação } & $-0,00^{*}$ & 0,00 & $0,00^{*}$ \\
\cline { 2 - 4 } & $(0,00)$ & $(0,00)$ & $(0,00)$ \\
\hline \multirow{2}{*}{ Sespesa } & $0,00^{*}$ & 0,00 & 0,00 \\
\hline \multirow{2}{*}{ Seniority } & $(0,00)$ & $(0,00)$ & $(0,00)$ \\
\hline & $-0,61$ & $-0,25$ & 0,03 \\
\hline \multirow{2}{*}{ Idade } & $(0,077)$ & $(0,18)$ & $(0,06)$ \\
\hline \multirow{2}{*}{ Ideologia } & $-0,93^{*}$ & $-19,9$ & $0,90^{* *}$ \\
\hline \multirow{2}{*}{ Constante } & $(0,45)$ & $(0,00)$ & $0,21)$ \\
\hline \multirow{2}{*}{ Vocação } & $0,05^{* *}$ & $-0,01$ & $(0,01)$ \\
\hline & $(0,01)$ & $(0,02)$ & 0,16 \\
\hline & 0,15 & $-1,15$ & $(0,29)$ \\
\hline & $(0,38)$ & $(0,78)$ & $-0,61^{*}$ \\
\hline & $-0,50$ & 0,12 & $(0,24)$ \\
\hline & $(0,31)$ & $(0,57)$ & $-0,15$ \\
\hline & 0,08 & 0,34 & $(0,29)$ \\
\hline & $(0,29)$ & $(0,59)$ & $-1,90$ \\
\hline
\end{tabular}

N: 1101

Pseudo $R^{2}: 0,10$

$$
{ }^{*} p<0,05,{ }^{* *} p<0,01
$$

Categoria de referência: ambição estática.

- Dados extraidos do Tribunal Superior Eleitoral. Fonte: Elaborada pelos autores.

Os resultados da regressão logística dispostos na Tabela 6 mostram que, quanto maior é a votação obtida pelo deputado na eleição anterior, maior será a sua probabilidade de buscar um cargo mais atrativo e menos a 
probabilidade de se aposentar ${ }^{14}$. A probabilidade de aposentar-se está diretamente relacionada com a idade. Os deputados que concorreram à prefeitura nas eleiçóes de 2004, 2008 e 2012 (antes de sus (re)eleição para deputado federal) e não alcançaram o objetivo da eleição, tiveram aumentadas as suas probabilidade de concorrerem a um cargo maior, e diminuídas as de se retirarem do jogo político.

Ser membro da coalizão também é um fator que aumenta a probabilidade de um deputado buscar a reeleição em relação a cargos mais altos. Segundo Borges e Sanches Filho (2016), os deputados pertencentes à coalizão de governo têm maior propensão de concorrer à reeleição devido ao alto nível de disputa intrapartidária para a formação da lista, o que é diferente nos partidos de oposição (no período, coincidiram com os partidos de direita) que não têm o mesmo nível de competitividade interna e privilegiam os candidatos com maior potencial de campanha. Os resultados do modelo de regressão da Tabela 6 mostram que as variáveis seniority, ideologia e vocação não foram estatisticamente significantes para explicar a escolha de cargos que os deputados federais concorreram no período em estudo.

O segundo modelo testado toma como variável dependente a decisão do deputado em concorrer à prefeitura no meio do mandato. Os resultados dispostos na Tabela 7 mostram que os deputados com maior votação na eleição anterior e com maior seniority tiveram maior probabilidade em concorrer à prefeitura. Os deputados pertencentes a partidos da coalizáo tiveram, significativamente, 2,3 vezes mais chances de concorrer a este cargo do que os deputados de oposição. Esse fato pode ser explicado pelo maior acesso a recursos que esses políticos detêm junto ao Executivo e aos líderes de seus partidos. Já os deputados de centro e de direita apresentaram probabilidade menor que os de esquerda em buscar prefeituras. Por fim, os deputados dos partidos com vocação presidencialista, PT e PSDB, têm maior probabilidade de disputarem esse cargo do que os demais, com 1,9 vezes mais chances de realizarem essa escolha. No entanto, é válido destacar que este resultado desse ser lido, de forma cautelosa, já que, nos testes

14 Lembramos que a categoria de referência é reeleição, ou ambição estática. 
de correlação realizados e apresentados na Tabela 4, não houve diferença significativa entre a vocação do partido e o fato de disputarem ou não prefeituras.

Tabela 7 - Regressão logística binária (VD: ambição: concorrer à prefeitura) ${ }^{\star}$

\begin{tabular}{lcc}
\hline Variáveis & Coeficiente & Erro \\
\hline Votação & $0,000^{*}$ & 0,000 \\
Despesa & 0,000 & 0,000 \\
Seniority & $0,126^{*}$ & 0,061 \\
Coalizão & $0,822^{* *}$ & 0,275 \\
Ideologia (centro/esquerda) & $-0,904^{* *}$ & 0,256 \\
Ideologia (direita/esquerda) & $-1,501^{* *}$ & 0,391 \\
Vocação & $0,629^{*}$ & 0,249 \\
Constante & $-1,599^{* *}$ & 0,21 \\
$\mathbf{N}: \mathbf{9 8 7}$ & &
\end{tabular}

Pseudo $\mathbf{R}^{2}: \mathbf{0 , 0 4 6}$
\[ \begin{array}{c}{ }^{*} p<0,05,{ }^{* *} p<0,01 \\ { }^{*} \text { Dados extraídos do Tribunal Superior Eleitoral. } \\ \text { Fonte: Elaborada pelos autores. }\end{array} \]

Quando se incluem todas as escolhas realizadas pelos deputados federais nas eleiçóes nacionais (Tabela 6), os partidos parecem não importar, visto que se candidatar à reeleição é a opção mais segura, individualmente, para os deputados federais. Já na Tabela 6 , o modelo apresentou resultados que corroboram com as hipóteses apresentadas neste artigo, pois sabemos que o cargo de deputado federal é fundamental para os partidos pelo seu alto nível de capital político. Por este motivo, é de se esperar que os partidos busquem deputados federais para disputas municipais importantes, já que estes apresentam grande probabilidade de sucesso; ademais, ressalta-se que isso tem mais relevância em partidos de esquerda do que de centro e de direita, dado o controle que os primeiros podem exercer sobre as escolhas dos deputados. 


\section{Considerações finais}

Qual o papel dos partidos políticos na definição das carreiras de seus filiados? Os estudos sobre carreira política têm privilegiado as variáveis individuais em detrimento de variáveis exógenas ao político, como o partido político. O propósito deste artigo foi incluir essa variável na análise das escolhas de carreira de deputados federais brasileiros, como forma de testar se partidos políticos têm importância nessas escolhas. $\mathrm{O}$ que observamos é que elas não são tão idiossincráticas como poderiam parecer, pois elas se diferenciam, conforme o tipo de partido a que eles pertencem, principalmente quando se considera a variável ideologia.

No entanto, é válido destacar que os resultados atribuem esse peso da variável partidária somente nas escolhas dos deputados ao concorrerem às prefeituras, visto que, nas eleiçóes nacionais, os deputados federais - tanto de esquerda quanto de direita - tendem, em geral, a escolher a reeleição, por ela oferecer menores custos individualmente e haver o peso da escolha individual dos parlamentares. A escolha pela ambição progressiva em eleiçóes nacionais levaria o deputado federal a concorrer a cargos de senador, governador e presidente da República, o que, evidentemente, tem um número de vagas em disputa muito menor do que para deputado federal.

Este artigo, portanto, apresenta a relevância da variável partidária para a escolha dos deputados em concorrer ou não às prefeituras. Ainda que essa estratégia tenha sido tomada, igualmente, por partidos relevantes nas disputas presidenciais ou não, o tipo de partido quanto à sua ideologia, definitivamente, parece nos ajudar a entender que essa escolha é importante para os partidos de esquerda que buscam mais esses cargos do que os que os partidos de centro e de direita. Esse achado vai ao encontro com o argumento presente na literatura de que os partidos de centro e de direita dáo muito mais autonomia aos seus políticos do que os partidos de esquerda.

Enfim, este artigo contribui com a literatura de carreiras políticas, conectando-a à de partidos políticos, sendo importante para entender que as escolhas de carreira realizadas pelos parlamentares devem ser compreendidas a partir da organização partidária à qual eles pertencem, e demonstrando que a ideologia é uma variável importante para se considerar em estudos futuros sobre a temática. 


\section{Referências}

ABRAMSON, P. R.; ALDRICH, J. H; ROHDE, D. W. Progressive ambition among United States Senators: 1972-1988. The Journal of Politics, v. 49, p. 1-35, 1987.

BRAGA, M. S. O processo partidário-eleitoral brasileiro: padrôes de competição política (19822002). São Paulo: Associação Editorial Humanitas/Fapesp, 2006.

BRAGA, M. S. S.; AMARAL, O. E. M.; implicações do processo de seleção de candidatos na competição partidária: o caso brasileiro. Revista de Sociologia e Política, v. 21, n. 46, p. 33-43 jun. 2013.

BIZZARRO-NETO, F. A. PMDB: organização e desenvolvimento em São Paulo (1994-2010). Orientadora: Rachel Meneguello. 2013. 199 f. Dissertaçáo (Mestrado em Ciência Política) - Programa de Pós-Graduação em Ciência Política, Universidade Estadual de Campinas, Campinas, 2013.

BLACK, G. S. A Theory of Political Ambition: Career Choices and the Role of Structural Incentives. American Political Science Review, v. 66, n. 1, p. 144-159, 1972.

BORCHERT, J. Ambition and Opportunity in Federal Systems: The Political Sociology of Political Career Patterns in Brazil, Germany, and the United States. APSA 2009 Toronto Meeting Paper, p. 21, 2009.

BORCHERT, J. Individual Ambition and Institutional Opportunity: A Conceptual Approach to Political Careers in Multi-level Systems. Regional \& Federal Studies, v. 21, n. 2, p. 117-140, maio 2011.

BORGES, A.; SANCHES FILHO, A. O. Federalismo, coalizóes de governo e escolhas de carreira dos deputados federais. Opiniáo Pública, v. 22, n. 1, p. 1-27, 2016.

BOTERO, F.; RENNÓ, L. Career Choice and Legislative Reelection: Evidence from Brazil and Colombia. Brazil Polítical Science Review, v. 1, p. 102-125, 2007.

CAREY, J. M.; SHUGART, M. Incentives to Cultivate a Personal Vote: a Rank Ordering of Electoral Formulas. Electoral Studies, v. 14, n. 4, p. 417-439, 1995.

CORTEZ, R. Eleiçóes majoritárias e entrada estratégica no sistema partidário-eleitoral brasileiro (1989-2006). Orientador: Fernando Limongi. 2009. 163 f. Tese (Doutorado em Ciência Política) - Programa de Pós-Graduação em Ciência Política, Universidade de São Paulo, São Paulo, 2009.

COSTA, D. L. S. Análise multinível dos padróes de carreira política dos deputados federais brasileiros: 2010-2014. Orientador: Vítor Eduardo Veras de Sandes Freitas. 108 f. Dissertação (Mestrado em Ciência Política) - Programa de Pós-Graduação em Ciência Política, Universidade Federal do Piauí, Teresina, 2018.

FERREIRA, D. P. PFL x PMDB: marchas e contramarchas (1982-2000). Goiânia: Alternativa, 2002 . 
FIGUEIREDO, A. C.; LIMONGI, F. Modelos de Legislativo: o Legislativo Brasileiro em Perspectiva Comparada. Revista Plenarium - Câmara dos Deputados, v. 1, p. 41-56, 2004.

GRAÇA, L. F. G.; SOUZA, C. P. R. Uso estratégico de eleiçóes alternadas? Efeitos da candidatura para prefeito sobre a votação dos concorrentes ao cargo de deputado federal no Brasil. Opiniáo Pública, Campinas, v. 20, n. 3, p. 326-345, dez. 2014.

KERBAUY, M. T. M. As eleições municipais de 2008: federaçōes partidárias ou partidos nacionais. Perspectivas, Sáo Paulo, v. 35, p. 15-33, 2009.

KIEWIET, D. R.; ZENG, L. an Analysis of Congressional Career Decisions, 1947-1986. American Political Science Review, v. 87, n. 4, p. 928-941, 1993.

KLASNJA, M; TITIUNIK, R. The incumbency curse: weak parties, term limits, and unfulfilled accountability. American Political Science Review, v. 111, n. 1, p. 129-148, 2017.

LEONI, E; PEREIRA, C.; RENNÓ, L. Estratégias para sobreviver politicamente: escolhas de carreiras na Câmara de Deputados do Brasil. Opiniáo Pública, Campinas, v. 9, n. 1, 2015.

LIMONGI, F.; CORTEZ, R. As eleições de 2010 e o quadro partidário. Novos estudos CEBRAP, São Paulo, n. 88, p. 21-37, dez. 2010.

MACIEL, N. Velhas raposas, novos governistas: o PMDB e a democracia brasileira. Orientador: Gláucio Ary Dillon Soares. 2014. 225 f. Tese (Doutorado em Ciência Política) - Programa de PósGraduação em Ciência Política, Universidade do Estado do Rio de Janeiro, Rio de Janeiro, 2014.

MAINWARING, S. Políticos, partidos e sistemas eleitorais: o Brasil numa perspectiva comparada. Novos Estudos, São Paulo, n. 29, p. 34-58, mar. 1991.

MARENCO, A. O que podemos explicar estudando carreiras políticas? In: MARENCO, A. (Org). Os eleitos: representação e carreiras políticas em democracias [online]. Porto Alegre: Editora da UFRGS, 2013. p. 31-51.

MARENCO, A.; SERNA, M. Por que carreiras políticas na esquerda e na direita não são iguais? Recrutamento legislativo em Brasil, Chile e Uruguai. Revista Brasileira de Ciências Sociais, São Paulo, v. 22, n. 64, p. 93-113, jun. 2007.

MELO, C. R. Nem tanto ao mar, nem tanto a terra: elementos para uma análise do sistema partidário brasileiro. In: MELO, C. R.; SÁEZ, M. A. (Org.). A democracia brasileira: balanço e perspectivas para o século 21. Belo Horizonte: UFMG, 2007. p. 267-302.

MELO, C. R.; CÂMARA, R. Estrutura da competição pela Presidência e consolidação do sistema partidário no Brasil. Dados, Rio de Janeiro, v. 55, n. 1, p. 71-117, 2012.

MENEGUELLO, R. Alguns aspectos da lógica de coalizóes partidárias. Textos para Discussáo CEPAL/IPEA, Brasília, n. 8, p. 9-45, 2010.

PEREIRA, C.; RENNÓ, L. "Should I Stay or Should I Go ?”: explaining political ambition by electoral success in Brazil. Journal of Politics in Latin America, v. 5, n. 3, p. 73-95, 2013. 
ROHDE, D. Risk-Bearing and Progressive Ambition: The Case of Members of the United States House of Representatives. American Journal of Political Science, v. 23, n 1, p. 1-26, 1979.

SAMUELS, D. J. Determinantes do voto partidário em sistemas eleitorais centrados no candidato: evidências sobre o Brasil. Dados, Rio de Janeiro, v. 40, n. 3, p. 493-533, 1997.

SAMUELS, D. J. Ambition and Competition: Explaining Turnover in the Brazilian Chamber of Deputies. Legislative Studies Quarterly, v. 25, n. 3, p. 481-497, 2000.

SAMUELS, D. J. Ambition, Federalism, and Legislative Politics in Brazil. New York: Cambridge University Press, 2003.

SAMUELS, D. Political Ambition, candidate recruitment, and legislative politics in Brazil. In: SIAVELIS, P. M.; MORGENSTERN, S. (Org.). Pathways to power: political recruitment and candidate selection in Latin America. Pennsylvania: The Pennsylvania State University Press, 2008, p. 76-91.

SAMUELS, D. Ambición política, reclutamiento de candidatos y política legislativa en Brasil. Postdata, v. 16, n. 2, p. 281-307, 2011.

SANDES-FREITAS, V. E. V. Alianças contextuais ou nacionalizadas? Análise das coligaçóes nas eleiçōes para prefeitos em 2012. Cadernos Adenauer, Rio de Janeiro, v. XIV, n. 2, p. 147-165, 2013.

SANDES-FREITAS, V. E. V. Alianças partidárias nos estados brasileiros: das coligaçōes às coalizōes de governo. Orientador: Rachel Meneguello. 2015. 317 f. Tese (Doutorado em Ciência Política) - Programa de Pós-Graduação em Ciência Política, Universidade Estadual de Campinas, Campinas, 2015.

SCHLESINGER, J. Ambition and politics: political careers in the United States. Chicago: Rand MacNally and Company, 1966. 


\section{Do political parties matter in defining political careers in Brazil?}

\section{Abstract}

This article aims to analyze whether political parties are important on the political career choices of Brazilian federal deputies. Therefore, this work is based on the theoretical contributions on political career that have shown that the main career pattern presented by congressmen is static, that is, seek for re-election (PEREIRA; RENNÓ, 2013). The explanation pointed out is that this choice is the safest, regardless of the parties to which they are affiliated. However, other authors have called attention to the need to verify the importance of factors that differentiate deputies in a more disaggregated analysis of political careers such as participation in the government coalition or opposition groups (BORGES; SANCHES FILHO, 2016), as well as the differences presented within the districts (COSTA, 2018; CORRÊA, 20I6). In addition, the party variable can be an important factor in defining the careers due to ideological differences between the parties (MARENCO; SERNA, 2007) and the strategic interests of the parties in the elections for Mayor in the big cities. Thus, this article aims to test if the party variable matters for the career choice of federal deputies, as well as the other variables portrayed in the literature. The results show that deputies of leftist parties and the government coalition are more likely to run for reelection and the city hall than those of the right and center.

Keywords: Political career. Political parties. Federal deputies. 